\title{
Papers
}

\section{Association of glycaemia with macrovascular and microvascular complications of type 2 diabetes (UKPDS 35): prospective observational study}

\author{
Irene M Stratton, Amanda I Adler, H Andrew W Neil, David R Matthews, Susan E Manley, \\ Carole A Cull, David Hadden, Robert C Turner, Rury R Holman on behalf of the UK Prospective \\ Diabetes Study Group
}

\begin{abstract}
Objective To determine the relation between exposure to glycaemia over time and the risk of macrovascular or microvascular complications in patients with type 2 diabetes.

Design Prospective observational study.

Setting 23 hospital based clinics in England, Scotland, and Northern Ireland.

Participants 4585 white, Asian Indian, and

Afro-Caribbean UKPDS patients, whether randomised or not to treatment, were included in analyses of incidence; of these, 3642 were included in analyses of relative risk.

Outcome measures Primary predefined aggregate clinical outcomes: any end point or deaths related to diabetes and all cause mortality. Secondary aggregate outcomes: myocardial infarction, stroke, amputation (including death from peripheral vascular disease), and microvascular disease (predominantly retinal photocoagulation). Single end points: non-fatal heart failure and cataract extraction. Risk reduction associated with a $1 \%$ reduction in updated mean $\mathrm{HbA}_{1 \mathrm{c}}$ adjusted for possible confounders at diagnosis of diabetes.

Results The incidence of clinical complications was significantly associated with glycaemia. Each 1\% reduction in updated mean $\mathrm{HbA}_{1 \mathrm{c}}$ was associated with reductions in risk of $21 \%$ for any end point related to diabetes $(95 \%$ confidence interval $17 \%$ to $24 \%$, $\mathrm{P}<0.0001), 21 \%$ for deaths related to diabetes $(15 \%$ to $27 \%, \mathrm{P}<0.0001), 14 \%$ for myocardial infarction ( $8 \%$ to $21 \%, \mathrm{P}<0.0001$ ), and $37 \%$ for microvascular complications (33\% to $41 \%, \mathrm{P}<0.0001)$. No threshold of risk was observed for any end point.

Conclusions In patients with type 2 diabetes the risk of diabetic complications was strongly associated with previous hyperglycaemia. Any reduction in $\mathrm{HbA}_{1 \mathrm{c}}$ is likely to reduce the risk of complications, with the lowest risk being in those with $\mathrm{HbA}_{1 \mathrm{c}}$ values in the normal range $(<6.0 \%)$.

\section{Introduction}

The UK prospective diabetes study (UKPDS), a clinical trial of a policy of intensive control of blood glucose after diagnosis of type 2 diabetes, which achieved a median haemoglobin $\mathrm{A}_{1 \mathrm{c}}\left(\mathrm{HbA}_{1 \mathrm{c}}\right)$ of $7.0 \%$ compared with $7.9 \%$ in those allocated to conventional treatment over a median 10.0 years of follow up, has shown a substantial reduction in the risk of microvascular complications, with a reduction in the risk of myocardial infarction of borderline significance. ${ }^{1}$ Complementary information for estimates of the risk of complications at different levels of glycaemia can be obtained from observational analyses of data during the study.

In patients with type 2 diabetes previous prospective studies have shown an association between the degree of hyperglycaemia and increased risk of microvascular complications, ${ }^{23}$ sensory neuropathy, ${ }^{34}$ myocardial infarction, ${ }^{256}$ stroke, ${ }^{7}$ macrovascular mortality, ${ }^{8-10}$ and all cause mortality. ${ }^{911-14}$ Generally, these studies measured glycaemia as being high or low or assessed glycaemia on a single occasion, whereas repeated measurements of glycaemia over several years would be more informative.

The existence of thresholds of glycaemia-that is, concentrations above which the risk of complications markedly increases-has not been studied often in patients with type 2 diabetes. The relative risk for myocardial infarction seems to increase with any increase in glycaemia above the normal range ${ }^{15}{ }^{16}$ whereas the risk for microvascular disease is thought to occur only with more extreme concentrations of glycaemia. ${ }^{17-19}$ The diabetes control and complications trial (DCCT) research group showed an association between glycaemia and the progression of microvascular complications in patients with type 1 diabetes for haemoglobin $\mathrm{A}_{1 \mathrm{c}}$ over the range of $6-11 \%$ after a mean of six years of follow up. ${ }^{20}$ No specific thresholds of glycaemia were identified above which patients were at greater risk of progression of retinopathy, increased urinary albumin excretion, or nephropathy. ${ }^{19-21}$ Nor has any threshold of fasting plasma glucose concentration been identified for cardiovascular deaths. ${ }^{22} 23$

We evaluated the relation between exposure to glycaemia over time and the development of macrovascular and microvascular complications and compared this with the results of the UKPDS trial of a policy of intensive control of blood glucose control.
Editorial by Tuomilehto Diabetes Trials Unit Oxford Centre for Diabetes,

Endocrinology and

Metabolism,

University of

Oxford, Radcliffe

Infirmary, Oxford

OX2 6HE

Irene M Stratton senior statistician

Amanda I Adler epidemiologist

Susan E Manley

biochemist

Carole A Cull

senior statistician

Rury R Holman

director

Division of Public Health and Primary Care, Institute of Health Sciences,

University of

Oxford, Oxford

OX3 7LF

H Andrew W Neil university lecturer in clinical epidemiology

Oxford Centre for Diabetes,

Endocrinology and Metabolism,

University of Oxford, Radcliffe Infirmary

David R Matthews consultant diabetologist

continued over

BMJ 2000;321:405-12

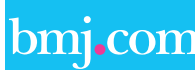

Details of

participating centres, staff, and committees and additional funding agencies are on the $B M J$ 's website. 
Royal Victoria Hospital, Belfast BT12 6BA

David Hadden

Diabetes Research Laboratories,

Oxford Centre for

Diabetes,

Endocrinology and

Metabolism,

University of

Oxford, Radcliffe

Infirmary

Robert C Turner

director

Correspondence to:

I M Stratton

irene.stratton@

dtu.ox.ac.uk

Professor Turner died unexpectedly after completing work on this paper consultant physician

\section{Methods}

\section{Participants recruited to the UKPDS}

Details are presented in the companion paper (UKPDS 36) published in this issue (see page 412).

Participants in observational analysis

Of 5102 patients, 4585 white, Asian Indian, and Afro-Caribbean patients who had haemoglobin $A_{1 c}$ $\left(\mathrm{HbA}_{1 \mathrm{c}}\right)$ measured three months after the diagnosis of diabetes were included in analyses of incidence rates. Of these, 3642 with complete data for potential confounders were included in analyses of relative risk. Complete data were required for all participants included in the multivariate observational analyses. For this reason there are fewer (3642) participants in these analyses than in the clinical trial, despite the inclusion of patients not randomised in the trial. Their characteristics are presented in table 1.

\section{Participants in UKPDS blood glucose control study}

After a three month dietary run-in period patients were stratified on the basis of fasting plasma glucose concentration and body weight. The 3867 patients who had fasting plasma glucose concentrations between 6.1 and $15.0 \mathrm{mmol} / \mathrm{l}$ and no symptoms of hyperglycaemia were randomised to a policy of conventional glucose control, primarily with diet, or to an intensive policy with sulphonylurea or insulin. ${ }^{124-26}$ The aim in the group allocated to conventional control $(\mathrm{n}=1138)$ was to obtain fasting plasma glucose concentration $<15$ $\mathrm{mmol} / \mathrm{l}$, but if concentrations rose to $\geqslant 15 \mathrm{mmol} / \mathrm{l}$ or symptoms of hyperglycaemia developed patients were secondarily randomised to non-intensive use of these pharmacological treatments, with the aim of achieving fasting plasma glucose concentrations $<15 \mathrm{mmol} / \mathrm{l}$ without symptoms. The aim in the group allocated to intensive control $(n=2729)$ was to achieve fasting plasma glucose concentration $<6 \mathrm{mmol} / \mathrm{l}$, primarily with a single pharmacological treatment. Details of treatments and their effect on glucose control have been published elsewhere. ${ }^{1}$

\section{Biochemical methods}

Biochemical methods have been reported previously. ${ }^{27}$ Haemoglobin $\mathrm{A}_{1 \mathrm{c}}$ was measured by high performance

Table 1 Characteristics of patients included in proportional hazards model measured after three month dietary run-in after diagnosis of diabetes and those included in UKPDS glucose control study. ${ }^{1}$ Figures are means (SD) unless stated otherwise

\begin{tabular}{lcc} 
& $\begin{array}{c}\text { Proportional hazards } \\
\text { model of observational } \\
\text { data }(\mathbf{n}=\mathbf{3 6 4 2})\end{array}$ & $\begin{array}{c}\text { Clinical trial of intensive } \boldsymbol{v} \\
\text { conventional blood glucose } \\
\text { control policy ( } \mathbf{n = 3 8 6 7 )}\end{array}$ \\
\hline Age (years) & $53(8)$ & $53(9)$ \\
\hline Proportion of men (\%) & 60 & 61 \\
\hline $\begin{array}{l}\text { Ethnicity }(\% \text { white/Asian Indian/Afro-Caribbean/ } \\
\text { other) }\end{array}$ & $82 / 10 / 8 / 0$ & $81 / 10 / 8 / 1$ \\
\hline Body mass index $\left(\mathrm{kg} / \mathrm{m}^{2}\right)$ & $27.7(5.3)$ & $27.5(5.2)$ \\
\hline Fasting plasma glucose $(\mathrm{mmol} /)^{\star}$ & $7.9(6.6-10)$ & $8.0(7.1-9.7)$ \\
\hline Haemoglobin $\mathrm{A}_{1 \mathrm{c}}(\%)$ & $7.1(1.8)$ & $7.1(1.5)$ \\
\hline Systolic blood pressure $(\mathrm{mm} \mathrm{Hg})$ & $135(19)$ & $135(20)$ \\
\hline Low density lipoprotein cholesterol $(\mathrm{mmol} / \mathrm{l})$ & $3.5(1.0)$ & $3.5(1.0)$ \\
\hline High density lipoprotein cholesterol $(\mathrm{mmol} / \mathrm{l})$ & $1.06(0.24)$ & $1.07(0.24)$ \\
\hline Triglyceride $(\mathrm{mmol} / \mathrm{l}) \dagger$ & $1.5(0.9-2.5)$ & 11.4 \\
\hline Albuminuria $(\%) \ddagger$ & 13.3 & \\
\hline
\end{tabular}

*Median (interquartile range).

†Geometric mean (1 SD range)

$\ddagger>50 \mathrm{mg} / \mathrm{l}$ in single morning sample. liquid chromatography (Biorad Diamat automated glycosylated haemoglobin analyser), the range for people without diabetes being $4.5 \%$ to $6.2 \%{ }^{27}{ }^{28}$ Baseline variables are quoted for measurements after the initial dietary run-in period.

\section{Glycaemic exposure}

Exposure to glycaemia was measured firstly at baseline as haemoglobin $\mathrm{A}_{1 \mathrm{c}}$ concentration and secondly over time as an updated mean of annual measurements of haemoglobin $A_{1 c}$ concentration, calculated for each individual from baseline to each year of follow up. For example, at one year the updated mean is the average of the baseline and one year values and at three years is the average of baseline, one year, two year, and three year values.

\section{Clinical complications}

The clinical end points and their definitions are shown in the box in the companion paper (UKPDS 36) published in this issue (see page 412).

\section{Statistical analysis}

\section{Incidence rates by category of glycaemia}

The unadjusted incidence rates were calculated by dividing the number of people with a given complication by the person years of follow up for the given complication within each category of updated mean haemoglobin $\mathrm{A}_{1 \mathrm{c}}$ concentration and reported as events per 1000 years of follow up. ${ }^{29}$ The categories were defined (median values in parentheses) as: $<6 \%$ (5.6\%), 6- <7\% (6.5\%), 7-<8\% (7.5\%), 8-<9\% (8.4\%), $9-<10 \%(9.4 \%)$, and $\geqslant 10 \%(10.6 \%)$ over the range of updated mean haemoglobin $\mathrm{A}_{\mathrm{cc}}$ of 4.6-11.2\% (1st-99th centile). Follow up time was calculated from the end of the initial period of dietary treatment to the first occurrence of that complication or loss to follow up, death from another cause, or to the end of the study on 30 September 1997 for those who did not have that complication. Hence, follow up time is equivalent to duration of diabetes. For myocardial infarction and stroke for participants who had a non-fatal followed by a fatal event, the time to the first event was used. The rates were therefore for single and not recurrent events. The median follow up time for all cause mortality was 10.4 years.

We calculated adjusted incidence rates for each category of updated mean haemoglobin $A_{1 c}$ using a Poisson regression model adjusted for male sex, white ethnic group, age at diagnosis 50-54 years, and duration of diabetes 7.5-12.5 years and expressed in events per 1000 person years of follow up. These parameters were chosen to reflect the median age and duration of diabetes and the modal ethnic group and sex.

\section{Hazard ratio and risk reduction}

To assess potential associations between updated mean haemoglobin $\mathrm{A}_{1 \mathrm{c}}$ and complications we used proportional hazards regression (Cox) models. Potential confounding risk factors included in all Cox models were sex, age, ethnic group, smoking (current/ever/never) at time of diagnosis of diabetes, and baseline high and low density lipoprotein cholesterol, triglyceride, presence of albuminuria ( $>50 \mathrm{mg} / \mathrm{l}$ measured in a single morning urine sample) measured after three months' 
dietary treatment, and systolic blood pressure represented by the mean of measures at two and nine months after diagnosis. The hazard ratio was used to estimate the relative risk. At each event time, the updated mean haemoglobin $A_{1 c}$ value for individuals with an event was compared with the updated value of those who had not had an event by that time. The updated mean value was included as a time dependent covariate to evaluate glucose exposure during follow up. ${ }^{20}{ }^{29}{ }^{30}$ It was included as a categorical variable in the categories of glycaemia listed above, with the lowest category $(<6 \%)$ as the reference category assigned a hazard ratio of 1.0 and with the highest category $\geqslant 9 \%$. (This is reflected in the point estimates as shown in figures 3 and 4.) Separate models, with updated mean haemoglobin $A_{1 c}$ as a continuous variable, were used to determine reduction in risk associated with a $1 \%$ reduction in haemoglobin $\mathrm{A}_{1 \mathrm{c}}$ (see regression lines in figures 3 and 4). We evaluated the presence of thresholds by visual inspection. The $95 \%$ confidence intervals were calculated on the basis of the floating absolute risk. ${ }^{31}$ Log linear relations are reported by convention. $^{132}$ The risk reduction associated with a reduction of $1 \%$ updated mean haemoglobin $A_{1 c}$ was calculated as $100 \%$ minus the reciprocal of the hazard ratio expressed as a percentage. The risk reduction from the continuous variable model associated with a $1 \%$ reduction in observed haemoglobin $A_{1 c}$ was compared with the risk reduction seen in the UKPDS intervention trial of an intensive versus a conventional policy of blood glucose control, for which no adjustment for potential confounders was required as they were balanced by randomisation. ${ }^{1}$

To assess whether the association between mean updated haemoglobin $\mathrm{A}_{1 \mathrm{c}}$ and complications was

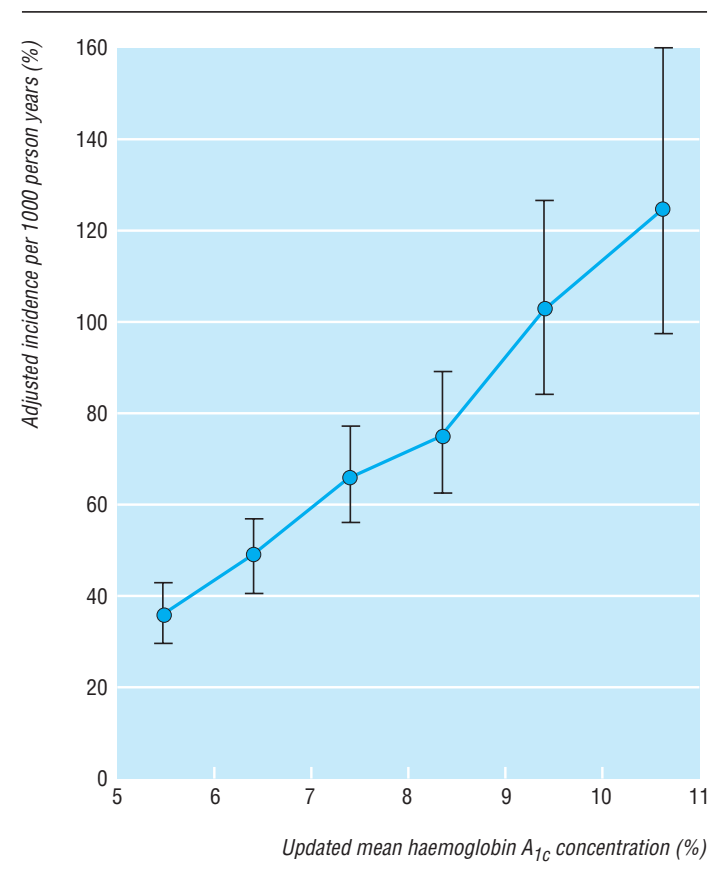

Fig 1 Incidence rate and 95\% confidence intervals for any end point related to diabetes by category of updated mean haemoglobin $A_{10}$ concentration, adjusted for age, sex, and ethnic group, expressed for white men aged 50-54 years at diagnosis and with mean duration of diabetes of 10 years

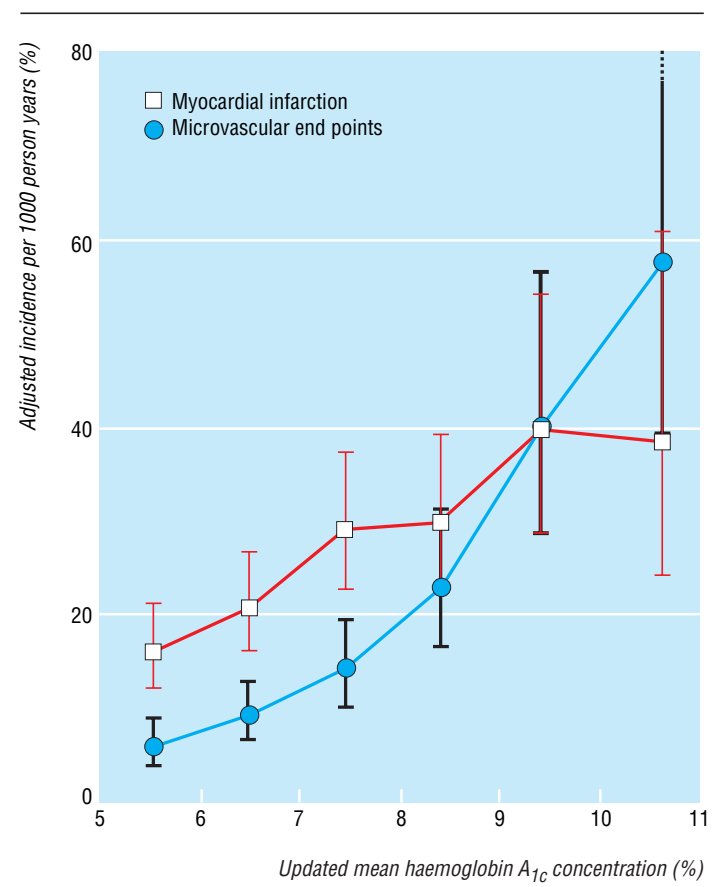

Fig 2 Incidence rates and 95\% confidence intervals for myocardial infarction and microvascular complications by category of updated mean haemoglobin $A_{1 c}$ concentration, adjusted for age, sex, and ethnic group, expressed for white men aged 50-54 years at diagnosis and with mean duration of diabetes of 10 years

independent of randomisation, separate models included mean updated haemoglobin $\mathrm{A}_{1 \mathrm{c}}$ and randomisation to either intensive or conventional policy, as well as all potential confounders listed above. The model for all end points related to diabetes included 3005 individuals.

Statistical analyses were performed with SAS version $6.12 .^{33}$

\section{Results}

The risk of each of the microvascular and macrovascular complications of type 2 diabetes and cataract extraction was strongly associated with hyperglycaemia as measured by updated mean haemoglobin $\mathrm{A}_{1 c}$. The incidence rates for any end point related to diabetes, adjusted for age, sex, ethnic group, and duration of diabetes, increased with each higher category of updated mean haemoglobin $A_{1 c}$, with no evidence of a threshold and with a threefold increase over the range of updated mean haemoglobin $\mathrm{A}_{1 \mathrm{c}}$ of $<6 \%$ (median $5.6 \%$ ) to $\geqslant 10 \%$ (median $10.6 \%$ ) (figs 1 and 2). The unadjusted and adjusted incidence rates are shown in table 2. Figure 2 shows the adjusted incidence rates for myocardial infarction and microvascular end points. The increase in the incidence rate for microvascular end points was greater over the range of increasing glycaemia than was the increase in the incidence rate for myocardial infarction. Thus at near normal concentrations of updated mean haemoglobin $\mathrm{A}_{1 \mathrm{c}}$ the risk of myocardial infarction was twice to three times that of a microvascular end point, whereas in the highest category of haemoglobin $\mathrm{A}_{1 \mathrm{c}}$ concentration $(\geqslant 10 \%)$ the risks were of the same order. 
Table 2 Incidence of complications in patients with type 2 diabetes by category of updated mean haemoglobin $A_{1 c}$ concentration (\%). Rates per 1000 person years' follow up adjusted in Poisson regression model to white men aged 50 to 54 years at diagnosis of diabetes and followed up for 7.5 to $<12.5$ years, termed "10 years" $(n=4585)$

\begin{tabular}{|c|c|c|c|c|c|c|}
\hline & $<6 \%$ & $6 \%$ to $<7 \%$ & $7 \%$ to $<8 \%$ & $8 \%$ to $<9 \%$ & $\mathbf{9} \%$ to $<10 \%$ & $\geqslant 10 \%$ \\
\hline \multicolumn{7}{|l|}{ Aggregate end points } \\
\hline \multicolumn{7}{|c|}{ Complications related to diabetes: } \\
\hline Events/person years & 229/9195 & $391 / 11432$ & $369 / 8464$ & $268 / 5605$ & $159 / 2542$ & $88 / 1334$ \\
\hline Adjusted rate $(95 \% \mathrm{Cl})$ & 35.9 (29.9 to 43.1$)$ & 48.7 (41.3 to 57.3 ) & 65.5 (55.5 to 77.2$)$ & 74.5 (62.6 to 88.8$)$ & 103.2 (84.2 to 126.5) & $124.9(97.3$ to 160.3$)$ \\
\hline \multicolumn{7}{|l|}{ Deaths related to diabetes: } \\
\hline Events/person years & $56 / 10113$ & $101 / 13143$ & $116 / 10054$ & $84 / 6595$ & $47 / 3137$ & $19 / 1537$ \\
\hline Adjusted rate $(95 \% \mathrm{Cl})$ & 8.9 (6.3 to 12.7) & $12.0(8.9$ to 16.3$)$ & 19.9 (14.8 to 26.7) & 23.5 (17.2 to 32.0$)$ & 29.5 (20.4 to 42.6) & $33.0(19.8$ to 55.1$)$ \\
\hline \multicolumn{7}{|l|}{ All cause mortality: } \\
\hline Events/person years & $112 / 10113$ & $207 / 13143$ & $188 / 10054$ & $123 / 6595$ & $64 / 3137$ & $26 / 1537$ \\
\hline Unadjusted rate & 11.1 & 15.8 & 18.7 & 18.7 & 20.4 & 16.9 \\
\hline Adjusted rate $(95 \% \mathrm{Cl})$ & 17.0 (13.1 to 22.0$)$ & 23.3 (18.5 to 29.2 ) & 30.0 (23.8 to 37.7 ) & 31.8 (24.7 to 40.8$)$ & 37.0 (27.3 to 50.2$)$ & 40.7 (26.5 to 64.5$)$ \\
\hline \multicolumn{7}{|c|}{ Fatal or non-fatal myocardial infarction: } \\
\hline Events/person years & $100 / 9870$ & $163 / 12590$ & $159 / 9579$ & $101 / 6331$ & $60 / 3016$ & $23 / 1490$ \\
\hline Adjusted rate $(95 \% \mathrm{Cl})$ & 16.0 (12.1 to 21.2$)$ & 20.8 (16.2 to 26.7) & 29.2 (22.8 to 37.4 ) & 30.0 (22.9 to 39.4$)$ & 39.6 (28.8 to 54.5 ) & 38.6 (24.4 to 61.0$)$ \\
\hline \multicolumn{7}{|l|}{ Fatal or non-fatal stroke: } \\
\hline Events/person years & $32 / 9916$ & $67 / 12869$ & $59 / 9822$ & $32 / 6424$ & $13 / 3062$ & $9 / 1509$ \\
\hline Unadjusted rate & 3.2 & 5.2 & 6.0 & 5.0 & 4.2 & 6.0 \\
\hline Adjusted rate $(95 \% \mathrm{Cl})$ & $4.3(2.6$ to 7.0$)$ & $6.6(4.4$ to 10.1$)$ & $8.3(5.4$ to 12.7$)$ & $7.4(4.5$ to 11.9$)$ & $6.7(3.5$ to 12.7$)$ & $12.0(5.7$ to 25.3$)$ \\
\hline \multicolumn{7}{|c|}{ Amputation or death from peripheral vascular disease: } \\
\hline Events/person years & $3 / 10018$ & $7 / 12993$ & $7 / 9897$ & $9 / 6492$ & $15 / 3061$ & $7 / 1502$ \\
\hline Unadjusted rate & 0.3 & 0.5 & 0.7 & 1.4 & 4.9 & 4.7 \\
\hline Adjusted rate $(95 \% \mathrm{Cl})$ & $1.2(0.4$ to 3.2$)$ & $1.2(0.5$ to 3.1$)$ & 2.6 (1.1 to 5.8$)$ & $4.0(1.8$ to 9.0$)$ & $10.9(5.0$ to 23.7$)$ & $12.2(4.6$ to 32.4$)$ \\
\hline \multicolumn{7}{|c|}{ Fatal or non-fatal microvascular disease: } \\
\hline Events/person years & $38 / 9814$ & 77/12 707 & $86 / 9438$ & $91 / 6185$ & $73 / 2855$ & $47 / 1432$ \\
\hline Unadjusted rate & 3.9 & 6.1 & 9.1 & 14.7 & 25.6 & 32.8 \\
\hline Adjusted rate $(95 \% \mathrm{Cl})$ & $6.1(4.1$ to 9.0$)$ & $9.3(6.7$ to 12.9$)$ & 14.2 (10.3 to 19.5$)$ & 22.8 (16.7 to 31.3$)$ & 40.4 (28.9 to 56.5$)$ & 57.8 (39.3 to 85.1$)$ \\
\hline \multicolumn{7}{|l|}{ Single end points } \\
\hline \multicolumn{7}{|l|}{ Heart failure: } \\
\hline Events/person years & $17 / 9967$ & $34 / 12928$ & $36 / 9782$ & 20/6432 & $10 / 3062$ & 10/1514 \\
\hline \multicolumn{7}{|l|}{ Cataract extraction: } \\
\hline Events/person years & $35 / 9841$ & $59 / 12763$ & 49/9692 & $45 / 6355$ & $19 / 3009$ & 19/1495 \\
\hline Unadjusted rate & 3.6 & 4.6 & 5.1 & 7.1 & 6.3 & 12.7 \\
\hline Adjusted rate $(95 \% \mathrm{Cl})$ & $4.1(2.5$ to 6.5$)$ & 4.5 (3.0 to 6.9$)$ & 4.9 (3.1 to 7.6$)$ & $6.9(4.4$ to 10.8$)$ & 6.6 (3.8 to 11.6$)$ & 14.4 (8.1 to 25.7$)$ \\
\hline
\end{tabular}

Person years, events, and unadjusted rates are for all patients.

The estimated hazard ratios associated with different categories of updated mean haemoglobin $\mathrm{A}_{1 \mathrm{c}}$ concentration, relative to the lowest category, are shown as $\log$ linear plots in figures 3 and 4 . Mortality related to diabetes and all cause mortality were both strongly associated with glycaemia $(\mathrm{P}<0.0001)$. The risk of each of the complications evaluated rose with increasing updated mean haemoglobin $A_{1 c}$ concentration both before and after adjustment for baseline variables including age, sex, ethnic group, lipid concentrations, blood pressure, smoking, and albuminuria. The decrease in risk for each $1 \%$ reduction in updated mean haemoglobin $\mathrm{A}_{1 \mathrm{c}}$ concentration is shown in table 3 and figures 3 and 4 . The glycaemia associated reduction in risk for microvascular end points and for amputation or death from peripheral vascular disease was greater (by $37 \%$ and $43 \%$ per $1 \%$ reduction in haemoglobin $\mathrm{A}_{1 \mathrm{c}}$ concentration, respectively, each $\mathrm{P}<0.0001$ ) than it was for myocardial infarction, stroke, and heart failure (by $14 \%(\mathrm{P}<0.0001), 12 \%(\mathrm{P}=0.035)$, and $16 \%(\mathrm{P}=0.021)$ per $1 \%$ haemoglobin $\mathrm{A}_{10}$, respectively) (fig 4 ). In models that included a variable for conventional control of blood glucose or intensive control with either sulphonylurea or insulin, updated mean haemoglobin
$\mathrm{A}_{1 c}$ remained associated with all complications, although for stroke and heart failure, where the numbers of events were lower than in the previous analyses, these were no longer significant. In these models, treatment of blood glucose per se had no association with any complication beyond that of mean updated haemoglobin $\mathrm{A}_{1 \mathrm{c}}$.

There was no indication of a threshold for any complication below which risk no longer decreased nor a level above which risk no longer increased. The updated mean haemoglobin $A_{1 c}$ showed steeper relations than did baseline haemoglobin $\mathrm{A}_{1 \mathrm{c}}$ (table 3 ), and when both glycaemic variables were included in a model for all complications of diabetes only updated mean haemoglobin $\mathrm{A}_{1 c}$ reached significance $(\mathrm{P}<0.0001)$

\section{Discussion}

This observational analysis shows highly significant associations between the development of each of the complications of diabetes, including mortality, across the wide range of exposure to glycaemia that occurs in patients with type 2 diabetes. This association 

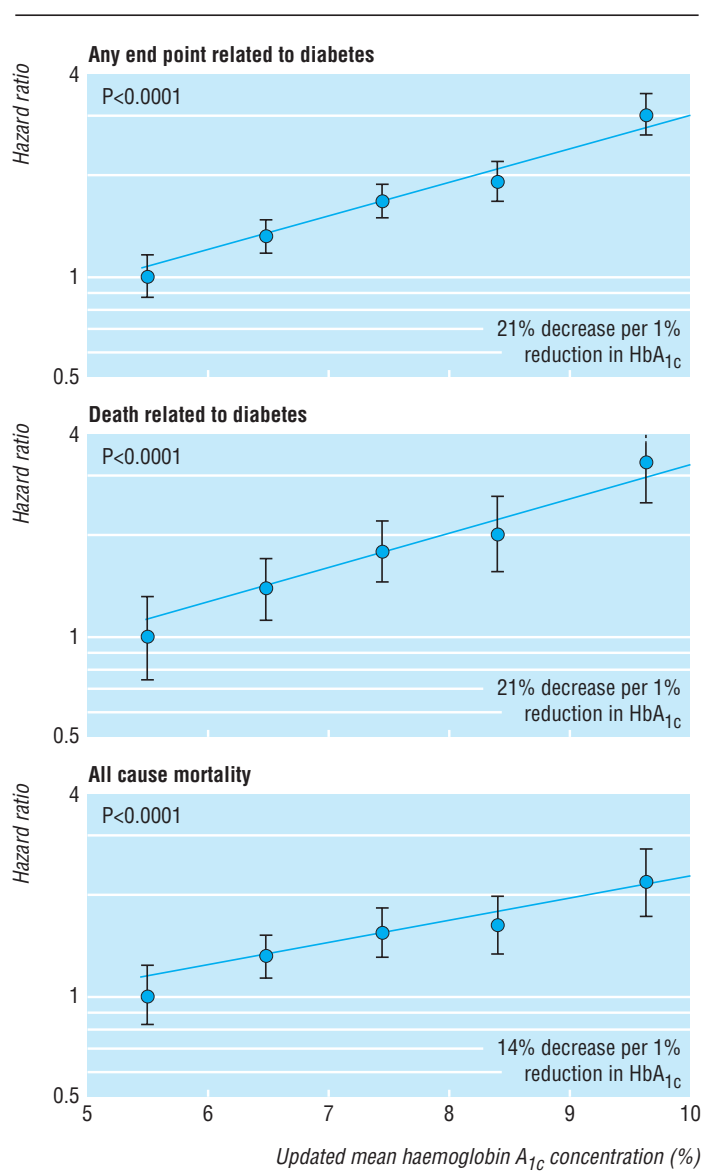

Fig 3 Hazard ratios, with 95\% confidence intervals as floating absolute risks, as estimate of association between category of updated mean haemoglobin $A_{1 c}$ concentration and any end point or deaths related to diabetes and all cause mortality. Reference category (hazard ratio 1.0) is haemoglobin $A_{1 c}<6 \%$ with log linear scales. $P$ value reflects contribution of glycaemia to multivariate model. Data adjusted for age at diagnosis of diabetes, sex, ethnic group, smoking, presence of albuminuria, systolic blood pressure, high and low density lipoprotein cholesterol, and triglycerides

remained after adjustment for other known risk factors, including age at diagnosis, sex, ethnic group, systolic blood pressure, lipid concentrations, smoking, and albuminuria. Each 1\% reduction in haemoglobin $\mathrm{A}_{1 \mathrm{c}}$ was associated with a $37 \%$ decrease in risk for microvascular complications and a $21 \%$ decrease in the risk of any end point or death related to diabetes. The association with glycaemia was less steep for stroke and heart failure, for which blood pressure is a major contributing factor. ${ }^{32} 3455$ In patients within the lowest category of updated mean haemoglobin $A_{1 c}$ the incidence of myocardial infarction was higher than that of microvascular disease. ${ }^{5}$ These results suggest that, in these people, the effect of hyperglycaemia itself may account for at least part of the excess cardiovascular risk observed in diabetic compared with non-diabetic people beyond that explained by the conventional risk factors of dyslipidaemia, hypertension, and smoking. ${ }^{36}$ The rate of increase of relative risk for microvascular disease with hyperglycaemia was greater than that for myocardial infarction, which emphasises the crucial role of hyperglycaemia in the aetiology of small vessel disease and may explain the greater rate of microvascular complications seen in populations with less satisfactory control of glycaemia.

\section{Relation to trial data}

This observational analysis provides an estimate of the reduction in risk that might be achieved by the therapeutic lowering of haemoglobin $\mathrm{A}_{1 \mathrm{c}}$ by $1.0 \%$, but it is important to realise that epidemiological associations cannot necessarily be transferred to clinical practice. Tissue damage from previous hyperglycaemia may not promptly be overcome, but the results are not inconsistent with those achieved by the policy of intensive glucose control in the clinical trial. ${ }^{1}$ This suggests that the reduction in glycaemia obtained over a median 10 years of follow up of the trial, comparing median haemoglobin $\mathrm{A}_{1 \mathrm{c}} 7.0 \%$ with $7.9 \%$, provided much of the benefit that could be expected from that degree of improved glycaemic control. Our results suggest that intensive treatment with sulphonylurea or insulin does not have an effect beyond that of lowering blood glucose concentration with respect to altering risk. The $16 \%$ risk reduction $(\mathrm{P}=0.052)$ in myocardial infarction in the clinical trial in the group allocated to a policy of intensive blood glucose control (associated
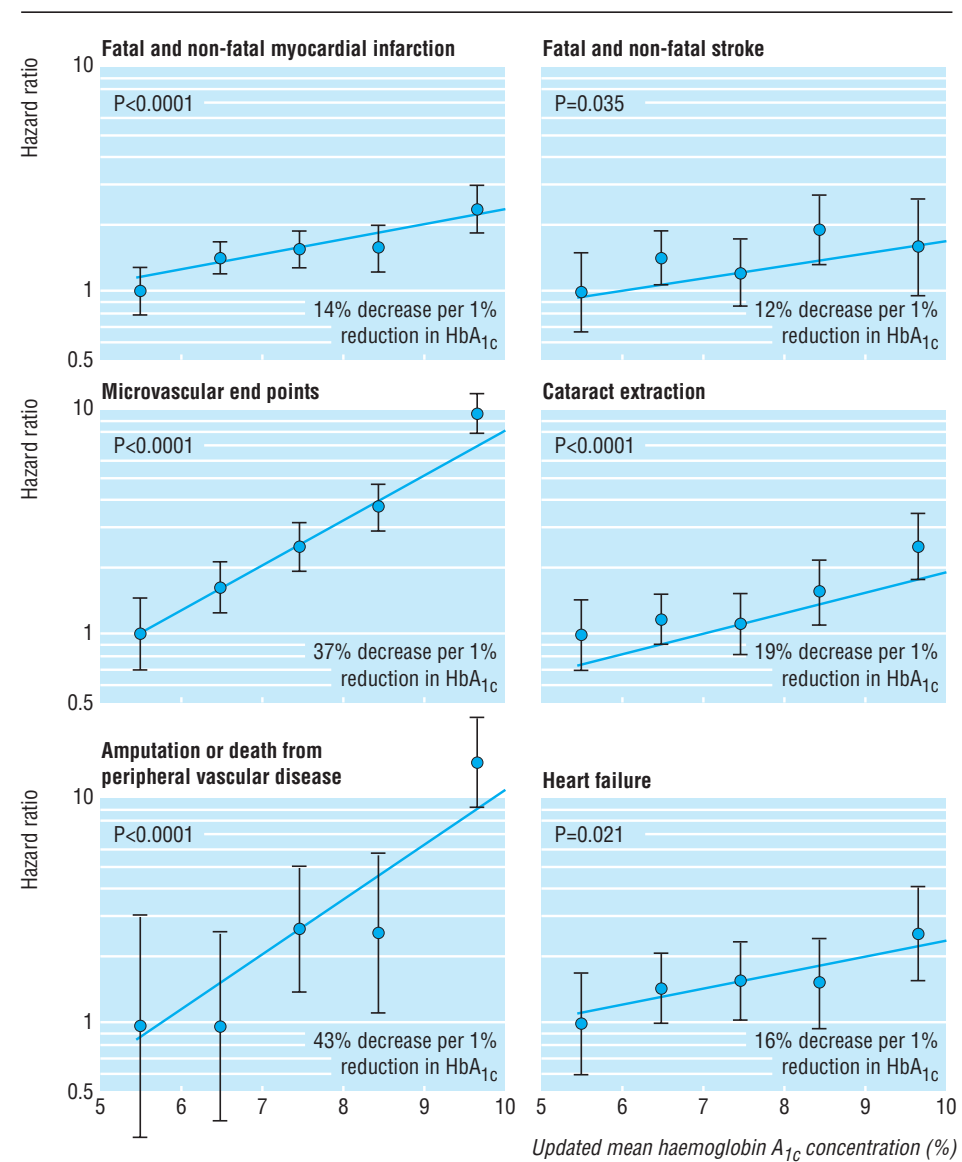

Fig 4 Hazard ratios, with 95\% confidence intervals as floating absolute risks, as estimate of association between category of updated mean haemoglobin $\mathrm{A}_{1 \mathrm{c}}$ concentration and myocardial infarction, stroke, microvascular end points, cataract extraction, lower extremity amputation or fatal peripheral vascular disease, and heart failure. Reference category (hazard ratio 1.0) is haemoglobin $A_{1 c}<6 \%$ with log linear scales. P value reflects contribution of glycaemia to multivariate model. Data adjusted for age at diagnosis of diabetes, sex, ethnic group, smoking, presence of albuminuria, systolic blood pressure, high and low density lipoprotein cholesterol, and triglycerides 
Table 3 Observational analysis of relation between glycaemic exposure and complications of diabetes as estimated by decrease in risk for $1 \%$ reduction in haemoglobin $\mathrm{A}_{1 \mathrm{c}}\left(\mathrm{HbA}_{\mathrm{c}}\right)$ concentration, measured at baseline and as updated mean, controlled for age at diagnosis of diabetes, sex, ethnic group, smoking, albuminuria, systolic blood pressure, high and low density lipoprotein cholesterol, and triglycerides $(\mathrm{n}=3642)$ compared with results of clinical trial of intensive $v$ conventional glucose control policy $(\mathrm{n}=3867)$

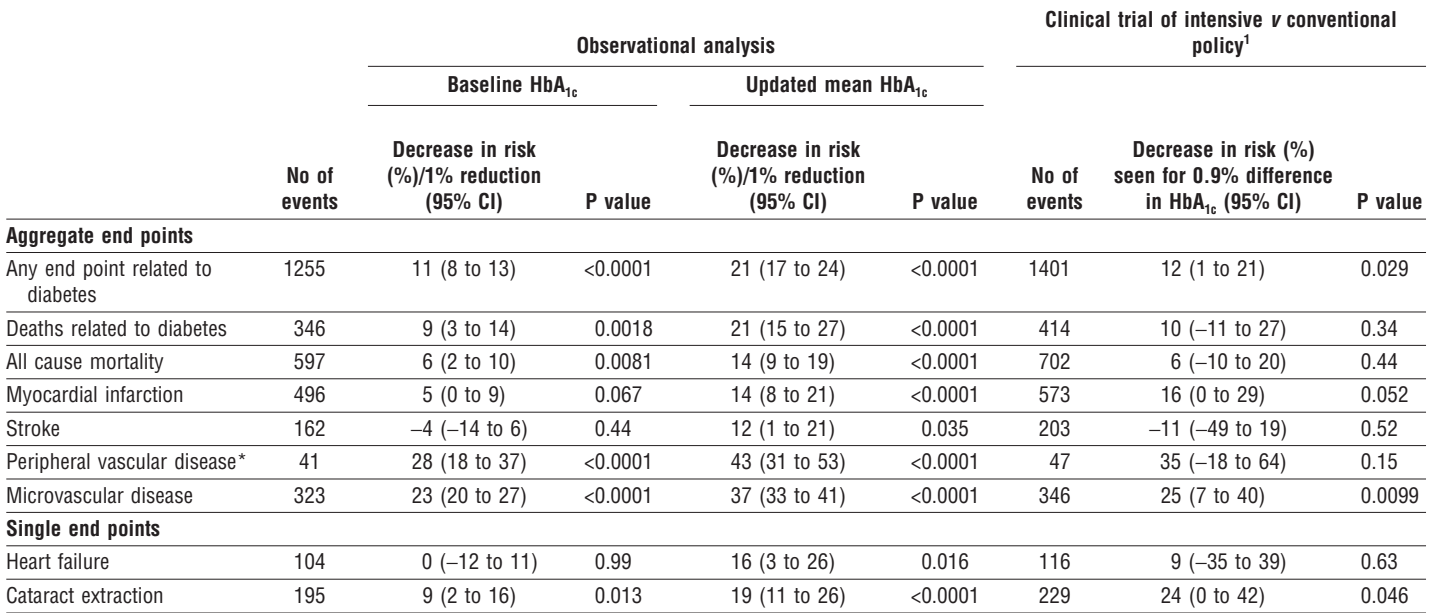

*Lower extremity amputation or fatal peripheral vascular disease.

with a $0.9 \%$ difference in haemoglobin $\mathrm{A}_{1 \mathrm{c}}$ ) was similar to the $14 \%$ risk reduction seen in the epidemiological analysis, which was associated with a $1 \%$ reduction in concentration of updated mean haemoglobin $\mathrm{A}_{1 \mathrm{c}}$. The UKPDS clinical trial evaluated a policy of intensive glucose control based primarily on single pharmacological treatments to enable evaluation of the individual treatments. Now that the UKPDS has shown that improved glucose control reduces the risk of complications and that the treaments used are safe in clinical practice, a larger reduction in haemoglobin $\mathrm{A}_{1 c}$ might be achieved by the earlier use of combination treatments or by the use of newer treatments, which could further reduce the risk of myocardial infarction.

The observational analysis extends the range of hyperglycaemia studied in the UKPDS by including participants who, throughout the study, had near

\section{What is already known on this topic}

The risk of developing complications of diabetes increases with increasing concentrations of hyperglycaemia

Reduction of hyperglycaemia in these individuals reduces the risk of complications

\section{What this study adds}

There is a direct relation between the risk of complications of diabetes and glycaemia over time

No threshold of glycaemia was observed for a substantive change in risk for any of the clinical outcomes examined

The lower the glycaemia the lower the risk of complications

The rate of increase of risk for microvascular disease with hyperglycaemia is greater than that for macrovascular disease normal glucose concentrations on dietary treatment alone and participants who could never be treated by dietary treatment alone. ${ }^{37}$ The UKPDS population was likely to be at lower risk of complications than other diabetic populations. Hence, the incidence rates we report are perhaps lower than might be observed in other diabetic populations as the cohort was newly diagnosed with diabetes, excluded old or ill patients, and contained a small proportion $(6 \%)$ of participants with impaired fasting glycaemia. ${ }^{38}$ None the less, the decrease in relative risk is unlikely to be different from other diabetic populations.

\section{Lack of thresholds}

We observed no thresholds of glycaemia for any type of complication of diabetes. This suggests that there is no specific target value of haemoglobin $A_{1 c}$ for which one should aim but that the nearer to normal the haemoglobin $A_{1 c}$ concentration the better. In reality, it is difficult to obtain and maintain near normal concentrations of haemoglobin $A_{1 c}$ in patients with type 2 diabetes, particularly in those with a high concentration of haemoglobin $\mathrm{A}_{1 \mathrm{c}}$ at diagnosis of diabetes. ${ }^{37}$ Intensification of treatment by adding insulin to improve the relatively modest reduction in glycaemia achieved with oral hypoglycaemic treatments can be constrained by reluctance from patients and providers because, in part, of side effects such as hypoglycaemia or weight gain. These observational analyses, together with the results of the clinical trial, however, indicate that any improvement in a raised haemoglobin $\mathrm{A}_{1 \mathrm{c}}$ concentration is likely to reduce the risk of diabetic complications.

The magnitude of the risk reduction associated with a $1 \%$ reduction in haemoglobin $A_{1 c}$ concentration for myocardial infarction and microvascular disease (mostly retinopathy) was consistent with that observed in a cohort of patients from Wisconsin. ${ }^{2}$ As in this analysis, a stronger association with haemoglobin $\mathrm{A}_{1 \mathrm{c}}$ concentration was observed for amputation than for ischaemic heart disease, possibly because glycaemia increases the risk of microvascular disease, neuropathy, 
and peripheral arterial disease, each of which increases the risk of amputation. ${ }^{41839-41}$ The estimated 14\% decrease in all cause mortality per $1 \%$ reduction in haemoglobin $\mathrm{A}_{1 \mathrm{c}}$ concentration was similar to that seen in other studies that have assessed glycaemia as haemoglobin $A_{1 c}$ as a continuous variable (per $1 \%$ change) in multivariate proportional hazards models.?

\section{Summary}

Both the observational and clinical trial analyses of an intensive glucose control policy suggest that even a modest reduction in glycaemia has the potential to prevent deaths from complications related to diabetes as cardiovascular and cerebrovascular disease account for $50-60 \%$ of all mortality in this and other diabetic populations. ${ }^{82-47}$ Individuals with very high concentrations of glycaemia would be most likely to benefit from reduction of glycaemia as they are particularly at risk from the complications of type 2 diabetes, but the data suggest that any improvement in glycaemic control across the diabetic range is likely to reduce the risk of diabetic complications.

The cooperation of the patients and many NHS and non-NHS staff at the centres is much appreciated. We thank Mr Dick Jelfs for the measurement of haemoglobin $A_{1 c}$. Details of participating centres can be found on the $B M J$ 's website.

Contributors: IMS selected the methodology, carried out the statistical analyses, coordinated the writing of the paper, and participated in the interpretation of results. AIA assisted with the writing of the paper and interpretation of results. HAWN DRM, and DH participated in interpretation and revision of the paper. SEM managed the biochemical aspects and participated in interpretation and revision of the paper. CAC participated in preparation of the database and interpretation and revision of the paper. RCT and RRH were the principal investigators, planned and designed the study, and participated in interpretation and revision of the paper. RCT was also responsible for the initial draft of the paper. RRH is guarantor.

Funding: The major grants for this study were from the UK Medical Research Council, the British Diabetic Association, the UK Department of Health, The National Eye Institute and The National Institute of Digestive, Diabetes and Kidney Disease in the National Institutes of Health, United States, The British Heart Foundation, Novo Nordisk, Bayer, Bristol-Myers Squibb, Hoechst, Lilly, Lipha, and Farmitalia Carlo Erba. Details of other funding companies and agencies, the supervising committees, and all participating staff can be found on the $B M P$ s website.

Competing interests: AIA has received fees for speaking from Bristol-Myers Squibb, SmithKline Beecham, and Pfizer. IMS has received support for attending conferences from Zeneca and Hoechst and fees for speaking from Hoechst. CAC has received support for attending conferences from BristolMyers Squibb, Novo Nordisk, and Pfizer and fees for speaking from Bristol-Myers Squibb and Novo Nordisk. DRM has received fees for speaking from Bristol-Myers Squibb, Novo Nordisk, SmithKline Beecham, and Lilly and research funding from Lilly. SEM has received support for attending conferences from Bayer and Novo Nordisk. RRH has received fees for consulting from Bayer, Boehringer Mannheim, Bristol-Myers Squibb, Hoechst, Lilly, Novo Nordisk, Pfizer, and SmithKline Beecham; support for attending conferences from Bayer, Bristol-Myers Squibb, Hoechst, Lilly, Lipha, Novo Nordisk, and SmithKline Beecham; and research funding from Bayer, BristolMyers Squibb, Lilly, Lipha, and Novo Nordisk.

1 UKPDS Group. Intensive blood glucose control with sulphonylureas or insulin compared with conventional treatment and risk of complication in patients with type 2 diabetes (UKPDS 33). Lancet 1998;352:837-53

2 Klein R. Hyperglycemia and microvascular and macrovascular disease in diabetes. Diabetes Care 1995;18:258-68.

3 Pirart J. Diabetes mellitus and its degenerative complications: a prospective study of 4,400 patients observed between 1947 and 1973 (part 1) Diabetes Care 1978;1:168-88.
4 Adler AI, Boyko EJ, Ahroni AJ, Stensel V, Forsberg RC, Smith DG. Risk factors for diabetic peripheral sensory neuropathy. Results of the Seattle prospective diabetic foot study. Diabetes Care 1997;20:1162-7.

5 UKPDS Group. Risk factors for coronary artery disease in non-insulin dependent diabetes (UKPDS 23). BMJ 1998:316:823-8.

6 Kuusisto J, Mykkänen L, Pyörälä K, Laakso M. NIDDM and its metabolic control predict coronary heart disease in elderly subjects. Diabetes 1994;43:960-7.

7 Lehto S, Ronnemaa T, Pyörälä K, Laakso M. Predictors of stroke in middle-aged patients with non-insulin-dependent diabetes. Stroke 1996;27:63-8

8 Standl E, Balletshofer B, Dahl B, Weichenhain B, Stiegler H, Hormann A, et al. Predictors of 10-year macrovascular and overall mortality in patients with NIDDM: the Munich general practitioner project. Diabetologia 1996;39:1540-5

9 Groeneveld Y, Petri H, Hermans J, Springer MP. Relationship between blood glucose level and mortality in type 2 diabetes mellitus: a systematic review. Diabet Med 1999;116:2-13.

10 Uusitupa MI, Niskanen LK, Siitonen O, Voutilainen E, Pyörälä K. Ten-year cardiovascular mortality in relation to risk factors and abnormalities in lipoprotein composition in type 2 (non-insulindependent) diabetic and non-diabetic subjects. Diabetologia 1993;36:1175-84

11 Wei M, Gaskill SP, Haffner SM, Stern MP. Effects of diabetes and level of glycaemia on all-cause and cardiovascular mortality. Diabetes Care 1998:21:1167-79.

12 Hanefeld M, Fischer S, Julius U, Schulze J, Schwanebeck U, Schmechel H, et al. Risk factors for myocardial infarction and death in newly detected NIDDM: the diabetes intervention study, 11-year follow-up. Diabetologia 1996;39:1577-83

13 Knuiman MW, Welborn TA, Whittall DE. An analysis of excess mortality rates for persons with non-insulin-dependent diabetes mellitus in Western Australia using the Cox proportional hazards regression model. Am J Epidemiol 1992;135:638-48.

14 Sasaki A, Uehara M, Horiuchi N, Hasegawa K. A long-term follow-up study of diabetic patients in Osaka, Japan: mortality and causes of death. Tohoku J Exp Med 1983;141(suppl):639-44.

15 Balkau B, Shipley M, Jarrett RJ, Pyorala K, Pyorala M, Forhan A, et al. High blood glucose concentration is a risk factor for mortality in middleaged nondiabetic men. Diabetes Care 1998;21:360-7.

16 Fuller JH, Shipley MJ, Rose G, Jarrett RJ, Keen H. Mortality from coronary heart disease and stroke in relation to degree of glycaemia: the Whitehall study. BMJ 1983;287:867-70

17 Jarrett RJ, Keen H. Hyperglycaemia and diabetes mellitus. Lancet 1976;ii:1009-12.

18 Pettitt DJ, Knowler WC, Lisse JR, Bennett PH. Development of retinopathy and proteinuria in relation to plasma glucose concentration in Pima Indians. Lancet 1980;ii:1050-2.

19 Krolewski AS, Laffel LM, Krolewski M, Quinn M, Warram JH. Glycosylated hemoglobin and the risk of microalbuminuria in patient with insulin-dependent diabetes mellitus. N Engl J Med 1995;332:1251-5.

20 DCCT Research Group. The absence of a glycemic threshold for the development of long-term complications: the perspective of the diabetes control and complications trial. Diabetes 1996;45:1289-98.

21 Orchard T, Forrest K, Ellis D, Becker D. Cumulative glycemic exposure and microvascular complications in insulin-dependent diabetes mellitus. Arch Intern Med 1997;157:1851-6.

22 Balkau B, Bertrais S, Ducimitière P, Eschwège E. Is there a glycemic threshold for mortality risk? Diabetes Care 1999;22:696-9.

23 Coutinho M, Gerstein HC, Wang Y, Yusuf S. The relationship between glucose and incident cardiovascular events: a metaregression analysis of published data from 20 studies of 95,783 individuals followed for 12.4 years. Diabetes Care 1999;22:233-40.

24 UKPDS Group. UK prospective diabetes study VIII: study design, progress and performance. Diabetologia 1991;34:877-90.

25 Manley SE, Cull CA, Holman RR. Relation of fasting plasma glucose on patients with type 2 diabetes in UKPDS randomised to and treated with diet or oral agents. Diabetes 2000:49(suppl 1):A180.

26 UKPDS Group. Effect of intensive blood-glucose control with metformin on complications in overweight patients with type 2 diabetes (UKPDS 34). Lancet 1998;352:854-65.

27 UKPDS Group. UK prospective diabetes study XI: biochemical risk factors in type 2 diabetic patients at diagnosis compared with age-matched normal subjects. Diabet Med 1994;11:534-44

28 Cull CA, Manley SE, Stratton IM, Neil HAW, Ross IS, Holman RR, et al. Approach to maintaining comparability of biochemical data during long-term clinical trials. Clin Chem 1997;43:1913-8.

29 Breslow NE, Day NE. The design and analysis of cohort studies. Statistical methods in cancer research II. Oxford: Oxford University Press, 1987.

30 Agresti A. Categorical data analysis. New York: Wiley, 1990.

31 Easton DF, Peto J, Babiker AG. Floating absolute risk: an alternative to relative risk in survival and case-control analysis avoiding an arbitrary reference group. Stat Med 1991;10:1025-35.

32 UKPDS Group. Tight blood pressure control and risk of macrovascular and microvascular complications in type 2 diabetes (UKPDS 38). $B M$ J $1998 ; 317: 703-13$

33 SAS. Version 6. Cary, North Carolina: SAS Institute, 1990.

34 MacMahon S, Peto R, Cutler J, Collins R, Sorlie P, Neaton J, et al. Blood pressure, stroke, and coronary heart disease. Part 1: prolonged differences in blood pressure: prospective observational studies corrected for the regression dilution bias. Lancet 1990;335:765-74

35 Adler AI, Stratton IM, Neil HAW, Yudkin JS, Matthews DR, Cull CA, et al. Association of systolic blood pressure with macrovascular and microvascular complications of type 2 diabetes (UKPDS 36): prospective observational study. BMJ 2000;321:412-9. 
36 Stamler J. Epidemiology, established major risk factors and the primary prevention of coronary heart disease. In: Parmley WW, Chatterjee K, eds. Cardiology. Philadelphia:JB Lippincott, 1987:1-41.

37 UKPDS Group. UK prospective diabetes study 24: relative efficacy of sulfonylurea, insulin and metformin therapy in newly diagnosed non-insulin dependent diabetes with primary diet failure followed for six years. Ann Intern Med 1998;128:165-75.

38 American Diabetes Association. Report of the expert committee on the diagnosis and classification of diabetes mellitus. Diabetes Care 1998;21(suppl 1):5-19.

39 Franklin GF, Shetterly SM, Cohen JA, Baxter J, Hamman RF. Risk factors for distal symmetric neuropathy in NIDDM. The San Luis Valley diabetes study. Diabetes Care 1994:1172-7.

40 Harris M, Eastman R, Cowie C. Symptoms of sensory neuropathy in adults with NIDDM in the US population. Diabetes Care 1993;16:1446-52. 41 Adler AI, Boyko EJ, Ahroni JH, Smith DG. Lower extremity amputation in diabetes mellitus: the independent effects of peripheral vascular disease, sensory neuropathy and foot ulcers. Diabetes Care 1999;22: $1029-35$
42 Adler AI, Matthews D, Holman RR, Turner RC. Type 2 diabetes and death: causes, estimated life expectancy and mortality rates-the UK prospective diabetes study. Diabetes 1998;47(suppl 1):A71.

43 Palumbo PJ, Elveback LR, Chu CP, Connolly DC, Kurland LT. Diabetes mellitus: incidence, prevalence, survivorship and causes of death in Rochester, Minnesota, 1945-1970. Diabetes 1976;25:566-73.

44 Panzram G. Mortality and survival in type 2 (non-insulin-dependent) diabetes mellitus. Diabetelogia 1987;30:123-31.

45 Goodkin G. Mortality in diabetes. A 20 year mortality study. J Occup Med $1975 ; 17: 716-21$.

46 Wetterhall SF, Olson DR, DeStefano F, Stevenson JM, Ford ES, German RR, et al. Trends in diabetes and diabetic complications, 1980-1987. Diabetes Care 1992;15:960-7.

47 Stamler J, Vaccaro O, Neaton JD, Wentworth D. Diabetes, other risk factors, and 12 year cardiovascular mortality for men screened in the multiple risk factor intervention trial. Diabetes Care 1993;16:434-44.

(Accepted 20 March 2000)

\title{
Association of systolic blood pressure with macrovascular and microvascular complications of type 2 diabetes (UKPDS 36): prospective observational study
}

\author{
Amanda I Adler, Irene M Stratton, H Andrew W Neil, John S Yudkin, David R Matthews, \\ Carole A Cull, Alex D Wright, Robert C Turner, Rury R Holman on behalf of the UK Prospective \\ Diabetes Study Group
}

Editorial by
Tuomilehto

Diabetes Trial Unit Oxford Centre for

Diabetes,

Endocrinology and

Metabolism,

University of

Oxford, Radcliffe

Infirmary, Oxford

OX2 6HE

Amanda I Adler epidemiologist

Irene M Stratton

senior statistician

Carole A Cull

senior statistician

Rury R Holman

director

Division of Public

Health and Primary

Care, Institute of

Health Sciences,

University of

Oxford, OX3 7LF

$\mathrm{H}$ Andrew W Neil

university lecturer in

clinical epidemiology

continued over

BMJ 2000;321:412-9

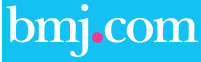

Details of participating centres, staff, and committees and additional funding agencies are on the BMJ's website

\section{Abstract}

Objective To determine the relation between systolic blood pressure over time and the risk of macrovascular or microvascular complications in patients with type 2 diabetes.

Design Prospective observational study. Setting 23 hospital based clinics in England, Scotland, and Northern Ireland.

Participants 4801 white, Asian Indian, and Afro-Caribbean UKPDS patients, whether randomised or not to treatment, were included in analyses of incidence; of these, 3642 were included in analyses of relative risk.

Outcome measures Primary predefined aggregate clinical outcomes: any complications or deaths related to diabetes and all cause mortality. Secondary aggregate outcomes: myocardial infarction, stroke, lower extremity amputation (including death from peripheral vascular disease), and microvascular disease (predominantly retinal photocoagulation). Single end points: non-fatal heart failure and cataract extraction. Risk reduction associated with a $10 \mathrm{~mm}$ $\mathrm{Hg}$ decrease in updated mean systolic blood pressure adjusted for specific confounders

Results The incidence of clinical complications was significantly associated with systolic blood pressure, except for cataract extraction. Each $10 \mathrm{~mm} \mathrm{Hg}$ decrease in updated mean systolic blood pressure was associated with reductions in risk of $12 \%$ for any complication related to diabetes $(95 \%$ confidence interval $10 \%$ to $14 \%, \mathrm{P}<0.0001), 15 \%$ for deaths related to diabetes ( $12 \%$ to $18 \%, \mathrm{P}<0.0001), 11 \%$ for myocardial infarction ( $7 \%$ to $14 \%, \mathrm{P}<0.0001)$, and $13 \%$ for microvascular complications $(10 \%$ to $16 \%$, $\mathrm{P}<0.0001)$. No threshold of risk was observed for any end point.
Conclusions In patients with type 2 diabetes the risk of diabetic complications was strongly associated with raised blood pressure. Any reduction in blood pressure is likely to reduce the risk of complications, with the lowest risk being in those with systolic blood pressure less than $120 \mathrm{~mm} \mathrm{Hg}$.

\section{Introduction}

The UK prospective diabetes study (UKPDS) has shown that a policy of tight control of blood pressure, which achieved a median blood pressure of 144/82 mm Hg compared with 154/87 mm Hg over median 8.4 years of follow up, substantially reduced the risk of microvascular disease, stroke, and deaths related to diabetes, ${ }^{1}$ but not myocardial infarction. Complementary information for estimates of the risk of complications including myocardial infarction at different levels of blood pressure can be obtained from observational analysis of the UKPDS data. This information can help to estimate the expected reduction in the risk of diabetic complications from a given change in blood pressure. It can also help to assess whether or not thresholds in blood pressure exist below which the risk of complications is substantially reduced. Such thresholds would have substantial influence on the establishment of guidelines on clinical care.

People with type 2 diabetes have a greater incidence of cardiovascular disease, cerebrovascular disease, and renal disease than the general population. Epidemiological studies suggest that relative hyperglycaemia accounts for part but not all of the increased risk. $^{2-7}$ Raised blood pressure is more common in people with type 2 diabetes than in the general population, ${ }^{8-12}$ and in people without diabetes it is a major risk factor for myocardial infarction and stroke. ${ }^{13}{ }^{14}$ Epidemiological studies of the role of blood 